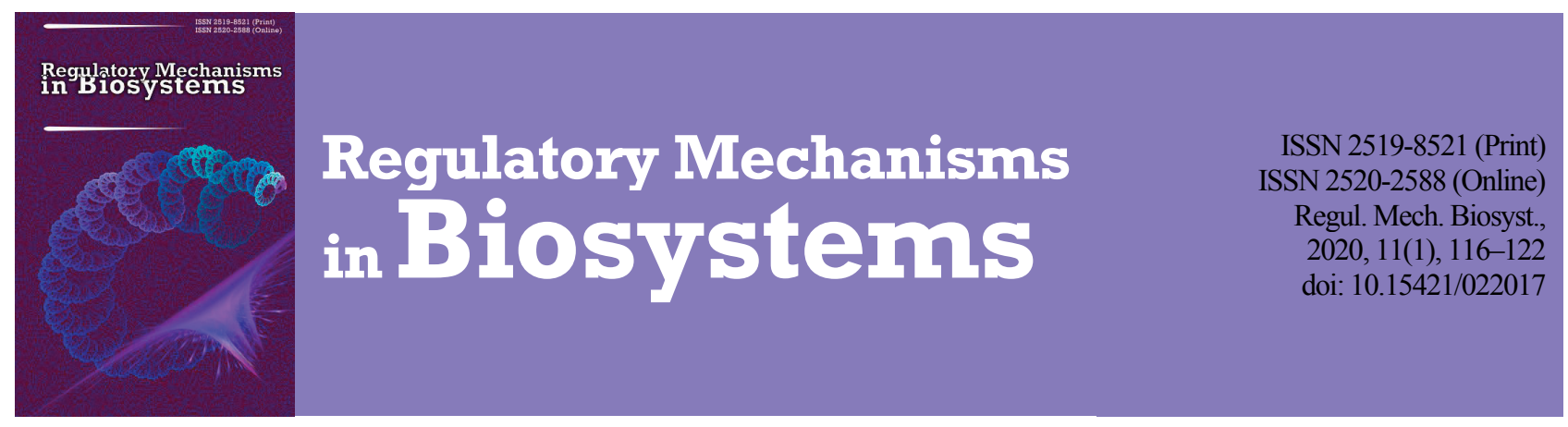

\title{
Morphogenesis, pigment content, phytohormones and productivity of eggplants under the action of gibberellin and tebuconazole
}

\author{
V. V. Rogach*, L. V. Voytenko**, M. M. Shcherbatiuk**, I. V. Kosakivska**, T. I. Rogach* \\ *Vinnytsia Mykhailo Kotsiubynskyi State Pedagogical University, Vinnytsia, Ukraine \\ **M. G. Kholodny Institute of Botany, National Academy of Sciences of Ukraine, Kyiv, Ukraine
}

Article info

Received 02.02.2020

Received in revised form 26.02 .2020

Accepted 27.02.2020

Vinnytsia Mykhailo Kotsiubynskyi State

Pedagogical University,

Ostrozhskogo st., 32, Vinnyt-

sia, 21000, Ukraine.

Tel: + 38-098-594-48-32

E-mail:rogach@@ukr.net

M. G. Kholodny Institute of Botany NASU,

Tereshchenkivska st., 2 ,

Kyiv, 01004, Ukraine.

Tel.: +38-097-238-67-57

E-mail:

lesyavoytenko@gmail.com

Rogach, V. V., Voytenko, L. V., Shcherbatiuk, M. M., Kosakivska, I. V., \& Rogach, T. I. (2020). Morphogenesis, pigment content, phytohormones and productivity of eggplants under the action of gibberellin and tebuconazole. Regulatory Mechanisms in Biosystems, 11(1), 116-122. doi:10.15421/022017

Regulation of growth and development of cultivated plants in order to optimize the production process is one of the main objectives of modern plant physiology. Both activators and growth inhibitors are used for this purpose. The effect of foliar treatment with $0.005 \%$ solution of gibberellic acid and $0.025 \%$ solution of antigibberellic preparation of tebuconazole on the morphogenesis, leaf structure, photosynthetic pigment content, balance of phytohormones and eggplant productivity cv. Diamond variety was investigated. The treatment with the preparations was carried out in the budding phase. The vegetation experiment was laid under soil and sand culture in vessels of a ten-liter capacity. The morphometric parameters were determined every 10 days, the mesostructure was studied in the leaves of the middle tier in the phase of fruit formation, chlorophyll content was measured in the raw material by spectrophotometric method. Analytical determination of phytohormones (indole-3-acetic acid, gibberellic, abscisic acids and cytokinins zeatin, zeatin-O-glucoside, zeatinriboside, isopentenyladenine and isopentenyladenosine) was performed by high performance liquid chromatography. Under the action of gibberellic acid, plant height increased significantly, and it decreased after its treatment with tebuconazole. The stimulator and inhibitor increased the number of leaves per plant, the weight of the leaf dry matter, the area of the individual leaf blade and the area of leaves per plant. Both preparations increased the weight of the raw material of the stems and roots, as well as the mass of dry matter of the whole plant. Under the action of tebuconazole, the content of chlorophylls in the leaves increased, while under the action of gibberellic acid it decreased. After treatment with gibberellic acid and tebuconazole, the thickness of the leaf blade increased due to chlorenchyma thickening. In the variant with gibberellic acid, the thickness of upper and lower epidermis increased, and in the variant with tebuconazole, these parameters decreased. Both growth regulators increased the volume of cells of the columnar parenchyma. The contet of endogenous gibberellic, indole-3-acetic and abscisic acids of the stems and especially in the leaves increased with the treatment of exogenous gibberellic acid, whereas after the application of tebuconazole the gibberellic and indole-3-acetic acid content of the stems decreased significantly and practically decreased to traces. Instead, the amount of abscisic acid increased. After treatment with exogenous gibberellic acid, the pool of cytokinins in the leaves significantly decreased. The inactive isoforms of the hormone zeatin-O-glucoside and isopentenyladenosine dominated in the stems. The effect of tebuconazole decreased the pool of cytokinins in the stems and increased in the leaves. In general, due to the multidirectional action, growth regulators positively influenced the elements of eggplant productivity. More effective was the retardant - tebuconazole. Therefore, the anatomic-morphological and structural-functional rearrangements in eggplants under the effects of exogenous gibberellic acid and tebuconazole are due to changes in the balance and distribution of endogenous hormones. Increased photosynthetic activity, stimulation of growth processes of some organs of the plant and inhibition of others enlarged the biological productivity of the culture.

Keywords: Solanum melongena; growth stimulators and inhibitors; morphometry; mesostructure; chlorophyll; plant hormones; crop productivity.

\section{Introduction}

Plant growth, development and productivity are controlled by complex physiological and biochemical mechanisms that are affected by a wide range of endogenous and exogenous factors. Exogenous factors of influence include temperature, water and light regimes, endogenous ones include the phytohormonal system that regulates metabolism and signalling (Ahammed \& Yu, 2016). The regulation of plant ontogenesis in order to effectively realize genetic potential and increase productivity is one of the key tasks of modern biological science. Exogenous growth regulators have been widely used in recent years (Rademacher, 2016).

There are two approaches in the regulation of plant growth and development. The first involves the use of exogenous hormones of stimulants: auxins, gibberellins and cytokinins or their synthetic analogues, which activate histo- and morphogenesis, accelerate proliferation and differentiation of cells, resulting in the formation of a branched root system, anatomical and morphological generative and morphological changes in vegetative and generative organs, increasing power, increasing photosynthetic activity (Rogach \& Rogach, 2015; Rohach, 2017; Khodanitska et al., 2019). With these changes, the synthesis of plastic compounds, the flow of which is directed to the generative and reserve organs, is enhanced (Kuryata et al., 2019b; Poprotska et al., 2019).

The second approach is to inhibit growth and development processes, resulting in anatomic-morphological and physiological-biochemical changes necessary to optimize the production process (Kuryata et al., 2016; Kuryata \& Kravets, 2018). The gibberellin inhibitors - retardants and ethylene products - are widely applied. They resemble native inhibitors: abscisic acid and ethylene, and phenolic inhibitors - quercetin- 
glycosyl-coumarate and paracumaric acid in terms of effects on the plant organism (Rademacher, 2016).

Plant gibberellin hormones stimulate activity of meristematic fabrics, first of all, the apical meristem. They enhance cell division and stretching (Rogach \& Rogach, 2015; Rogach et al., 2016). Preparations with antigibberellin activity are able to inhibit and even remove apical dominance (Kuryata \& Polyvanyi, 2018b), which leads branch strengthening, which is important in terms of regulation of the productivity (Kuryata \& Golunova, 2018; Kuryata \& Polyvanyi, 2018a; Kuryata et al., 2019a).

More leaves, flowers and fruits are formed and yields are increasing (Kuryata \& Khodanitska, 2018). The excess of assimilates that accumulates as a result of slowing down growth processes goes to the organs and tissues that are formed and actively developed. The vast majority of cultivated plants are economically valuable tissues and organs (Shevchuk et al., 2019).

The change in the balance and activity of endogenous phytohormones under the action of exogenous natural and synthetic releasing compounds opens the possibility to artificially control the processes of plant growth and development. Thus, the treatment of seedlings of Malus hupehensis (Pamp.) with synthetic auxin indole-3-butiric acid enhanced growth processes, thickened the stem and induced the development of lateral roots. At the same time, the content of indole-3-acetic acid (IAA) and zeatinriboside increased and the amount of abscisic (ABA) and gibberellic $\left(\mathrm{GA}_{3}\right)$ acids decreased. Under the action of the preparation, the relationship between IAA and $\mathrm{ABA}$ and between $\mathrm{ABA}$ and $\mathrm{GA}_{3}$ (1-3) increased (Mao et al., 2018). Foliar treatment with exogenous $\mathrm{GA}_{3}$ significantly offset the negative effects of salinization, enhanced growth and increased the productivity of Solanum lycopersicum L. The balance of phytohormones changed: the content of active gibberellins, cytokinins, indole-3-acetic acid and abscisic acid increased (Khalloufi et al., 2017). Gibberellic acid, secreted by rhizobacterium Pseudomonas putida $\mathrm{H}-2-3$, increased the resistance of soybean plants to drought and salinity, increased linear growth, the accumulation of crude and dry matter in shoots and increased the chlorophyll content. In soybean leaves, endogenous $\mathrm{GA}_{3}$ and ABA content increased (Kang et al., 2014). After treatment of Brassica campestris L. plants with exogenous gibberellic acid under conditions of cold stress, an increase in linear dimensions was observed, the number of buds and flowers increased. An increase in the content of endogenous gibberellic and indole-3-acetic acids and cytokinins has been reported in the shoot apex (Song et al., 2019). The treatment of grapevine with a mixture of native and synthetic auxins increased the content of endogenous zeatinriboside, gibberellic, and indole-3-acetic acids and decreased the amount of abscisic acid, which positively affected the engraftment of cuttings (Zhou et al., 2020).

Retardants - inhibitors of gibberellins - are a widely used group of growth regulators. Thus, the treatment of flax plants with paclobutrazole and prohexadione in closed soil reduced the plant height, accelerated seed maturation and increased fruit amount. Under the action of paclobutrazole, the oil content of the seeds decreased and it increased under the influence of prohexadione. Both inhibitors reduced the content of endogenous gibberellins in the seeds (Kim et al., 2018). Retardants metconazole and paclobutrazole - inhibited the synthesis of gibberellins and increased carbohydrate accumulation in mango fruits (Cavalcante et al., 2020). The content of cytokinins and abscisic acid in the mango buds after application of paclobutrazol in the soil increased and the level of gibberellins significantly decreased (Upreti et al., 2013). Spraying of Brassica campestris L. plants with uniconazole inhibited growth, slowed budding and flowering, and altered endogenous gibberellins (Song et al., 2019). The gibberellin inhibitors - uniconazole and ethephon - inhibited the growth of maize plants, facilitated a better accumulation of dry matter and faster grain filling, which increased the content of abscisic acid, zeatin and zeatinriboside and decreased the level of gibberellic acid. The accumulation of abscisic acid and cytokinins correlated positively with the rate of grain filling. The use of the triazole derivative of uniqueosole retardant was more effective than the ethylene product of ethephone (Ahmad et al., 2019).

The treatment of barley with uniconazole under salt stress conditions improved plant resistance, stimulated the accumulation of abscisic acid and cytokinins, and reduced the content of gibberellic and indole-3acetic acids. Protein and proline content increased as a result of the preparation in the grain (Bakheta \& Hussein, 2014). The use of uniconazole increased the productivity of the aquatic plant Landoltia punctata (G. Mey.) by $10.1 \%$, it also increased the amount of chlorophylls and the intensity of photosynthesis and altered the hormonal balance. The action of the preparation increased the content of cytokinins and abscisic acid and decreased gibberellins (Liu et al., 2015).

A research paper (Jabir et al., 2017) reported that the use of gibberellic acid and triazole derivative of paclobutrazole, as well as their mixtures, affected growth, endogenous phytohormone content and productivity of Raphanus sativus L. Paclobutrazole inhibited the linear growth of radish plants, increased cell proliferation, increased root mass and size. Under the action of gibberellic acid, the growth of the aboveground part was activated and the underground was inhibited, the mass of the root crop remained practically unchanged. Under the influence of the mixture of preparations intermediate values of the mass of the underground and aboveground parts of the plant were observed. Paclobutrazole significantly reduced the content of endogenous gibberellins, and exogenous gibberellic acid, on the contrary, slightly increased. The auxin content did not change regardless of the preparations used.

Consequently, the analysis of scientific literature has shown that exogenous growth regulators optimize the production process and improve the quality of agricultural products. This is due to changes in hormonal balance, anatomic-morphological and physiological-biochemical transformations. At the same time, no comparative systematic studies of the dynamics of accumulation and distribution of endogenous phytohormones due to the influence of multi-vector exogenous growth regulators on Solanum melongena L. plants have been performed. Therefore, the purpose of the study was to study the nature of accumulation and localization of endogenous phytohormones under the action of exogenous growth regulators and their effect on morphogenesis, leaf apparatus and eggplant productivity.

\section{Materials and methods}

The vegetation experiment was laid in soil-sand culture in opaque plastic containers with a 10-liter capacity. Grey forest podzolized largedusted medium-loamy soil mixed with sand in a ratio of $3: 1$ was used. The plants were grown under controlled conditions at $+20 / 17{ }^{\circ} \mathrm{C}$ (day/night), light intensity $690 \mu \mathrm{mol} /\left(\mathrm{m}^{2} \cdot \mathrm{s}\right)$, photoperiod $16 / 8 \mathrm{~h}$ (day/night), relative humidity of $65 \pm 5 \%$, the substrate humidity was maintained at $60 \%$ of the total humidity. They were watered daily with a solution of Knop at the rate of $250 \mathrm{~mL}$ per vessel.

Eggplants cv. Diamond variety were treated once to complete leaf steeping with $0.005 \%$ gibberellic acid $\left(\mathrm{GA}_{3}\right)$ solution (Power Grown, USA) and $0.025 \%$ Tebuconazole (EW-250) solution (Bayer, Germany) in the budding phase on June 10, 2018 (sowing in a greenhouse 03.03.18, placement in vessels 26.05.18). The control plants were treated with water. The repetition of the growing experiment is tenfold.

Morphological analysis was performed every 10 days from the day of treatment. To determine the mass of individual organs, they were weighed on a laboratory balance. Leaf area was determined by the diecut method (AOAC, 2010). The average area of the leaf blade was determined by multiplying the length of the leaf blade by its width and by a conversion factor of 0.75 .

The leaf mesostructure was analyzed during carpogenesis (30 days after treatment). The plant material was stored in a mixture of equal parts of ethyl alcohol, glycerol, water with the addition of $1 \%$ formalin. The size of individual cells of chlorenchyma was determined on the preparations obtained by the method of partial maceration of the tissues of the leaf. Maceration agent is a 5\% solution of acetic acid in hydrochloric acid $(2 \mathrm{~mol} / \mathrm{L})$. Leaves of the middle tier, which completed the growth, were selected for an anatomical analysis. The size of the anatomical elements was determined on a microscope Mykmed-1 (RF) using an eyepiece micrometer MOV-1-15 $\times(\mathrm{RF})$. The repetition of the experiment was thirty-five times.

The content of chlorophylls was determined in the raw material by spectrophotometric method on a spectrophotometer SF-16 (RF). The 
experiment was repeated five times (AOAC, 2010). To determine the phytohormones, 2-gramm weights of the material were triturated in liquid nitrogen and homogenized in $10 \mathrm{ml}$ extraction solution (methanol, water, formic acid in a ratio of $15: 4: 1$ ) and extracted during 24 hours. The extracts were centrifuged for $30 \mathrm{~min}$. at $15000 \mathrm{rpm}$ at + $4{ }^{\circ} \mathrm{C}$ on a Janetski K-24 centrifuge from Germany. The supernatants were drained, and $5 \mathrm{~mL}$ of the extraction solution was added to the precipitate and kept for another 30 minutes, then re-centrifuged. The combined supernatants were evaporated to $5 \mathrm{~mL}$ with a Typ 350P vacuum evaporator (Poland). Further purification of phytohormones was performed by the method (Kosakivska et al., 2020) on two solid phase SPE C18 columns, Sep-Pak Plus, Waters and SPE Oasis MCX, 6 cc / 150 mg, Waters. Column $\mathrm{C} 18$ was used to remove lipophilic substances, proteins and pigments. On the SPE Oasis MCX column, sorption of indolyl acetic, abscisic, gibberellic acids and cytokinins was performed. Elution of indolylacetic, abscisic, gibberellic acids was performed with $100 \%$ methanol, cytokinins - with alkaline eluent $-60 \mathrm{~mL}$ of $100 \%$ methanol and $2.5 \mathrm{~mL}$ of $26 \%$ ammonia was brought to a volume of $100 \mathrm{~mL}$ with ultra-pure water. The resulting eluent was evaporated to dryness in a vacuum rotary evaporator at a temperature not exceeding $+40{ }^{\circ} \mathrm{C}$. The dry residue of each fraction was reduced to $200 \mu \mathrm{L}$ with $45 \%$ methanol before analysis.

Analytical determination of phytohormones was performed by high performance liquid chromatography on an Agilent 1200 LC liquid chromatograph with a G $1315 \mathrm{~V}$ diode-matrix detector (USA) together with an Agilent G6120A single-quadrupole mass spectrometer. For the chromatographic separation, an Agilent ZORBAX Eclipse Plus C18 column with a lipophilic-modified sorbent was used, the particle size of which was $5 \mu \mathrm{m}$ (reverse phase chromatography). After chromatogramphic separation of the $20 \mu \mathrm{L}$ sample components with a methanol solvent system, ultra-pure water, acetic acid in a volume ratio of $45: 54.9$ : 0.1 , IAA and ABA were detected in the UV absorption region at analytical wavelengths of 280 and $254 \mathrm{~nm}$. After separation of the samples with a solvent system of acetonitrile, ultra-pure water, acetic acid (30 : $69.9: 0.1$, gibberellic acid was detected by the mass detector signal. The samples with cytokinins were separated by a solvent system of methanol, water, acetic acid ( $35: 64.5: 0.5)$, and detection was carried out at $269 \mathrm{~nm}$. The velocity of the solvent mobile phase during the detection of indolyl acetic and abscisic acids was $0.7 \mathrm{~mL} / \mathrm{min}$, gibberellic acid and cytokinins $-0.5 \mathrm{~mL} / \mathrm{min}$. Unlabelled indole-3-acetic, abscisic, gibberellic acid, trans-zeatin-O-glucoside ( $\mathrm{t}-\mathrm{ZG})$, trans-zeatin (t-Z), transzeatinriboside (t-ZR) were used as standards for the construction of the calibration tables, isopentenyladenine (iP) and isopentenyladenosine (iPA) manufactured by Sigma-Aldrich (USA).

The content of analytes in the samples was monitored using a combined mass spectrometer (electrospray and chemical ionization at atomspheric pressure) with negative ionization of analyte molecules during the analysis of IAA, $\mathrm{GA}_{3}, \mathrm{ABA}$ and positive during CTC analysis. MSD SIM signal was used for quantitative analysis of $\mathrm{GA}_{3}$ (setting $50 \%$ of scan time of mass ionized molecule/charge 345 detector). If the phytohormone content was less than $2.01 \mathrm{ng} / \mathrm{g}$ of fresh weight substance, then the table indicates the value as traces. The experiments were performed in three biological and three analytical repetitions. Analysis and calculation of phytohormone content was performed using Agilent OpenLAB CDS ChemStation Edition software (rev. C.01.09).

The results were statistically processed using the Statistica $6.0 \mathrm{com}-$ puter program (StatSoft Inc., USA). One-factor dispersion analysis was used (differences between the mean values were calculated by Bonferroni-corrected ANOVA, considered to be significant at $\mathrm{P}<0.05$ ) (Van Emden, 2008).

\section{Results}

Foliar eggplant treatment in the budding phase with $0.005 \%$ aqueous gibberellic acid and $0.025 \%$ aqueous tebuconazole affected the rate of growth processes. During the growing season, the plants treated with gibberellic acid solution prevailed in shoot height, whereas in the first half of the growing season, the growth of plants did not differ significantly from that of the control samples, and in the second half it was inhibited. In the phase of fruit formation, the linear dimensions of plants treated with gibberellic acid exceeded the control samples by $36.7 \%$, whereas under the effects of tebuconazole they were $6.9 \%$ lower than the control ones (Fig. 1).

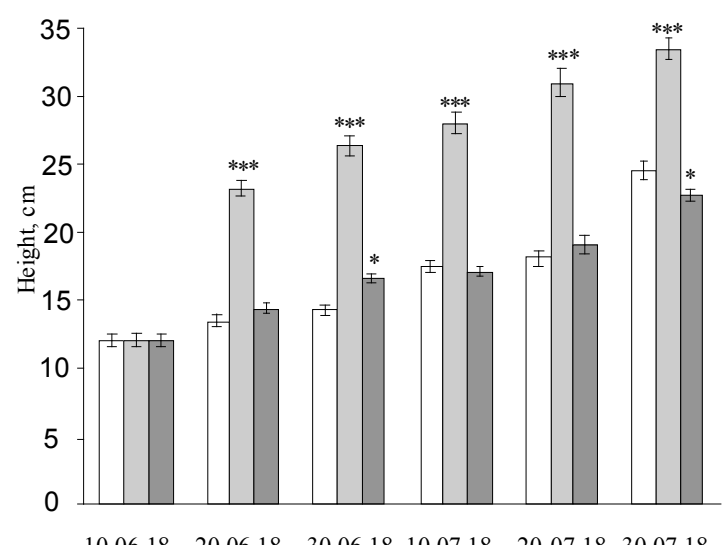

Fig. 1. Influence of foliar treatment with solutions of gibberellic acid and tebuconazole on the height of Solanum melongena L. cv. Diamond variety: treatment in budding phase 10.06.2018; $\mathrm{n}=5 ; \mathrm{x} \pm \mathrm{SE}$; white - control, light grey $-0.005 \%$ gibberellic acid, dark grey $0.025 \%$ tebuconazole; differences between the mean values were calculated using the Bonferroni-corrected ANOVA criterion, considered to be significant at $\mathrm{P}<0.05 ; *-\mathrm{P}<0.05 ; * *-\mathrm{P}<0.01$;

$* * *-\mathrm{P}<0.001$ compared to control at this stage of vegetation

Since the leaf is the main donor of plastic substances in the plant, the influence of growth regulators on the leaf apparatus has been analyzed. It is found that after treatment with gibberellic acid and tebuconazole solutions, the number of leaves per plant increased by $12.4 \%$ and $15.3 \%$, respectively (Fig. 2).

Under the action of growth regulators, the weight of leaf dry matter increased. Under the influence of the retardant, this index increased by $2.30 \pm 0.114 \mathrm{~g}$ per plant, whereas after treatment with gibberellic acid it increased by only $0.56 \pm 0.020 \mathrm{~g}$ (Table 1 ). Both growth regulators increased the mass of dry matter in stems and roots. Under the treatment with gibberellic acid, the mass of the stalk increased by $2.9 \pm 0.05 \mathrm{~g}$ and the root mass by $3.8 \pm 0.16 \mathrm{~g}$. Under the influence of tebuconazole, the mass of the stalk exceeded the control value by $5.0 \pm 0.14 \mathrm{~g}$, and the root mass - by $0.56 \pm 0.02 \mathrm{~g}$ (Table 1$)$. Growth regulators also influenced the dry matter accumulation of the whole plant. In the fruit formation phase gibberellic acid induced an increase in dry weight of $1.9 \pm$ $0.11 \mathrm{~g}$, and tebuconazole - by $2.3 \pm 0.09 \mathrm{~g}$ (Table 1).

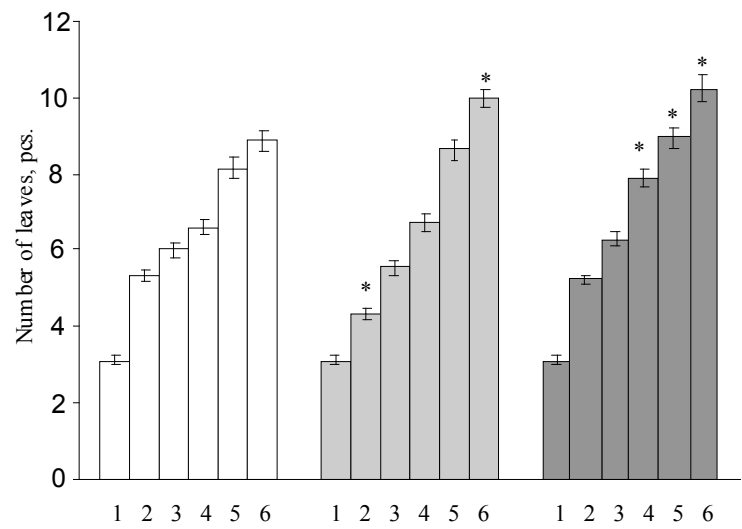

Fig. 2. Influence of foliar treatment with solutions of gibberellic acid and tebuconazole on the number of leaves on Solanum melongena $\mathrm{L}$. cv. Diamond varieties: treatment in the budding phase 10.06.2018; $\mathrm{n}=10 ; \mathrm{x} \pm \mathrm{SE}$; white - control, light grey $-0.005 \%$ gibberellic acid, dark grey $-0.025 \%$ tebuconazole; differences between the mean values were calculated using the Bonferroni-corrected ANOVA criterion: $*_{-} \mathrm{P}<0.05 ; * *-\mathrm{P}<0.01 ; * * *-\mathrm{P}<0.001$ compared to control in this phase of vegetation; 1 - date of processing; $2-10$; $3-20 ; 4-30 ; 5-40 ; 6-50$ th day after processing 
The area of leaves on the plant is one of the main indicators that affect the crop yield. It is found that the area of leaf blade after treatment with the retardant increased during the whole research period. The use of exogenous gibberellic acid induced an increase in leaf area only in the second half of the growing season. Treatment with the phytohormone and retardant led to an increase in leaf area during carpogenesis by 8.7 and $12.5 \mathrm{~cm}^{2}$, respectively (Fig. 3), and by the end of the study period leaf area increased by $18.5 \%$ and $38.6 \%$, respectively (Fig. 4) Under the action of growth regulators, the number of flowers per plant also increased.

An indicator of the effectiveness of the assimilation apparatus is the content and ratio of photosynthetic pigments. Therefore, the effect of exogenous growth regulators on the number of chlorophylls in eggplant leaves was investigated. It was found that the amount of chlorophylls in the leaves during the growing season increased significantly under the effects of tebuconazole. In the fruit-forming phase, this indicator exceeded the control by $23.1 \%$. In the first half of the study period, the content of chlorophylls under the action of gibberellic acid had an indicator close to the control sample, and at the end of the experiment it decreased by $9.0 \%$ (Fig. 5).

\section{Table 1}

Influence of foliar treatment with gibberellic acid and tebuconazole solutions on the morphological parameters of Solanum melongena $\mathrm{L}$. $\mathrm{cv}$. Diamond $(\mathrm{n}=10, \mathrm{x} \pm \mathrm{SE})$

\begin{tabular}{lccc}
\hline \multicolumn{1}{c}{ Indicator } & $\begin{array}{c}\text { Control } \\
\text { sample }\end{array}$ & $\begin{array}{c}\text { Gibberellic } \\
\text { acid }\end{array}$ & Tebuconazole \\
\hline Leaves mass of dry matter, g & $6.5 \pm 0.23$ & $7.1 \pm 0.29$ & $8.9 \pm 0.36^{* * * *}$ \\
Stem mass of dry matter, g & $4.1 \pm 0.18$ & $6.9 \pm 0.22^{* * *}$ & $9.1 \pm 0.32^{* * *}$ \\
Roots mass of dry matter, g & $3.0 \pm 0.12$ & $6.8 \pm 0.28^{* * *}$ & $3.5 \pm 0.14^{*}$ \\
Whole plant mass of dry matter, g & $3.0 \pm 0.11$ & $4.9 \pm 0.21^{* * *}$ & $5.3 \pm 0.23^{* * *}$ \\
Number of flowers per plant, pcs. & $3.3 \pm 0.15$ & $5.1 \pm 0.21^{* * *}$ & $5.0 \pm 0.22^{* *}$ \\
\hline
\end{tabular}

Note: treatment of plants in the budding phase was done on 10.06. 2018, fixation of indicators in the phase of the beginning of fruit formation; * $-\mathrm{P}<0.05$; ** $\mathrm{P}<0.01 ; * * *-\mathrm{P}<0.001$, one-line comparisons by means of the difference between the mean values were calculated using the Bonferroni-corrected criterion ANOVA.

Leaf mesostructural organization is an important indicator that determines the effectiveness of the photosynthetic apparatus of the plant and significantly affects its productivity. It is found that after treatment with tebuconazole, chlorenchyma thickened by $31.9 \pm 0.13 * \mu \mathrm{m}$, and after application of gibberellic acid - by $76.8 \pm 1.64 * \mu \mathrm{m}$. In general, the thickness of the leaf blade after the application of gibberellic acid increased by $46.7 \%$, while after the treatment with tebuconazole - by $7.1 \%$. Exogenous gibberellic acid and tebuconazole increased the volume of cells of the columnar parenchyma by $83.4 \%$ and $25.7 \%$, respectively, but the cell size of the spongy parenchyma did not change significantly (see Table 2).

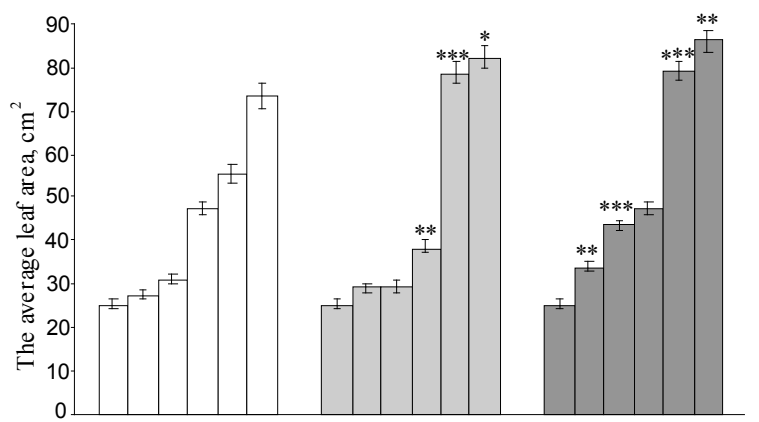

Fig. 3. Influence of foliar treatment with solutions of gibberellic acid and tebuconazole on the area of leaf blade of Solanum melongena $\mathrm{L}$. cv. Diamond variety: treatment in the budding phase done on 10.06. 2018; $\mathrm{n}$

$=10 ; \mathrm{x} \pm \mathrm{SE}$; black - control, light grey $-0.005 \%$ gibberellic acid, dark grey $-0.025 \%$ tebuconazole; 1 - date of processing; $2-10 ; 3-20$;

$4-30 ; 5-40 ; 6-50$ th day after treatment; differences between the mean values were calculated using the Bonferroni-corrected ANOVA criterion: $*_{-} \mathrm{P}<0.05 ; * *-\mathrm{P}<0.01 ; * * *-\mathrm{P}<0.001$ compared to control at this stage of vegetation

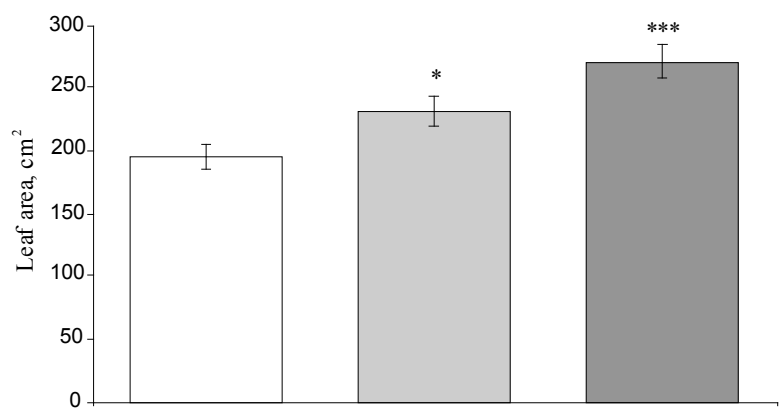

Fig. 4. Influence of foliar treatment with gibberellic acid and tebuconazole solutions on the leaf area of Solanum melongena L. cv. Diamond: budding phase 10.06.2018; $\mathrm{n}=10 ; \mathrm{x} \pm \mathrm{SE}$; white - control, light grey $-0.005 \%$ gibberellic acid, dark grey $-0.025 \%$ tebuconazole; differences between the mean values were calculated using the

Bonferroni-corrected ANOVA criterion: ${ }^{*}-\mathrm{P}<0.05$; ** $-\mathrm{P}<0.01$; $* * *-\mathrm{P}<0.001$ compared to the control at this stage of vegetation

\section{Table 2}

Influence of foliar treatment with gibberellic acid and tebuconazole solutions on mesostructural indices of leaves of Solanum melongena $\mathrm{L}$. cv. Diamond ( $\mathrm{x} \pm \mathrm{SE}, \mathrm{n}=35)$

\begin{tabular}{lccc}
\hline \multicolumn{1}{c}{ Indicator } & $\begin{array}{c}\text { Control } \\
\text { sample }\end{array}$ & $\begin{array}{c}\text { Gibberellic } \\
\text { acid }\end{array}$ & Tebuconazole \\
\hline The thickness & 210.3 & 308.1 & 225.1 \\
of the leaf blade, $\mu \mathrm{m}$ & \pm 3.91 & $\pm 6.96^{* * *}$ & $\pm 3.92^{*}$ \\
The thickness & 33.8 & 41.9 & 26.1 \\
of the upper epidermis, $\mu \mathrm{m}$ & \pm 1.90 & $\pm 1.47^{* *}$ & $\pm 1.54^{* *}$ \\
The thickness & 154.2 & 231.2 & 186.3 \\
of the chlorenchyma, $\mu \mathrm{m}$ & \pm 5.45 & $\pm 7.09^{* * *}$ & $\pm 4.95^{* * *}$ \\
The thickness & 21.7 & 35.9 & 13.4 \\
of the lower epidermis, $\mu \mathrm{m}$ & \pm 0.96 & $\pm 1.40^{* * *}$ & $\pm 0.63^{* * *}$ \\
The volume of cells of the & 16208 & 29719 & 20369 \\
columnar parenchyma, $\mu \mathrm{m}{ }^{3}$ & \pm 682.3 & $\pm 1311.2^{* * *}$ & $\pm 1062.2^{* *}$ \\
The length of the cells & 23.0 & 22.8 & 18.4 \\
of the spongy parenchyma, $\mu \mathrm{m}$ & \pm 0.95 & \pm 0.71 & $\pm 0.86^{* *}$ \\
The width of the cells & 19.7 & 17.1 & 16.4 \\
of the spongy parenchyma, $\mu \mathrm{m}$ & \pm 0.77 & \pm 0.69 & \pm 0.59 \\
\hline
\end{tabular}

Note: see Table 1.

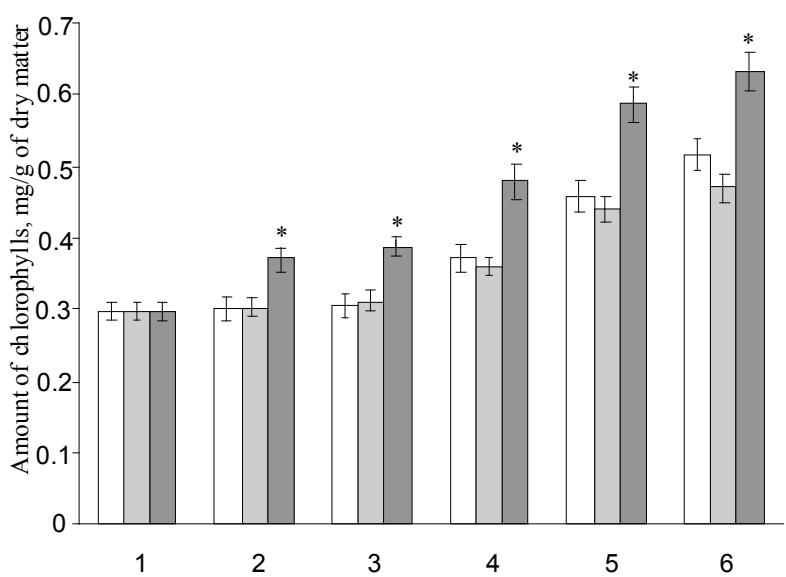

Fig. 5. Influence of foliar treatment with gibberellic acid and tebuconazole solutions on chlorophyll $(a+b)$ content in leaves of Solanum melongena L. cv. Diamond. processing in the budding phase 10.06.2018; $\mathrm{n}=10 ; \mathrm{x} \pm$ $\mathrm{SE}$; black - control, light grey $-0.005 \%$ gibberellic acid, dark grey $0.025 \%$ tebuconazole; 1 - date of processing; $2-10 ; 3-20 ; 4-30$;

$5-40 ; 6-50$ th day after treatment; differences between the mean values were calculated using the Bonferroni-corrected ANOVA criterion:

${ }^{*}-\mathrm{P}<0.05 ;{ }^{*}-\mathrm{P}<0.01 ; * * *-\mathrm{P}<0.001$ compared to the control sample at this stage of vegetation

The influence of foliar treatment of plants with gibberellic acid and tebuconazole solutions on the dynamics of accumulation and features of localization of endogenous indole-3-acetic, gibberellic and abscisic acids in the eggplant organs was analyzed. In control plants, indole-3- 
acetic acid and gibberellic acid dominated in the stem, where their content was, respectively, 8.5 and 2.5 times higher than in the leaves. Instead, abscisic acid dominated in the leaves, where its content was 1.5 times higher than in the stems. Exogenous gibberellic acid increased the content of endogenous hormones. Thus, in leaves the level of indole-3acetic acid increased by 12.3 , gibberellic acid - by 3.6 , abscisic acid by 2.1 times, while in the stem - by $1.2,1.5$ and 1.8 times. The most meaningful changes in the action of exogenous gibberellic acid occurred in the accumulation of indole-3-acetic acid (Fig. 6).

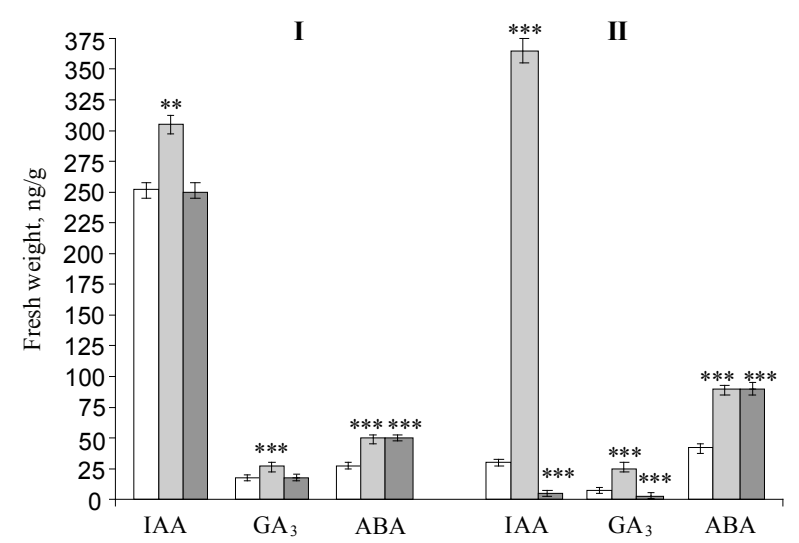

Fig. 6. Influence of foliar treatment with gibberellic acid and tebuconazole solutions on the content of endogenous phytohormones in stems and leaves of Solanum melongena L. cv. Diamond: treatment in budding phase 10.06.2018; $\mathrm{n}=6 ; \mathrm{x} \pm \mathrm{SE}$; white - control, light grey $-0.005 \%$ gibberellic acid, dark grey $-0.025 \%$ tebuconazole; differences between the mean values were calculated using the Bonferroni-corrected ANOVA criterion: ${ }^{*}-\mathrm{P}<0.05 ; * *-\mathrm{P}<0.01 ; * * *-\mathrm{P}<0.001$

Under the exogenous treatment of tebuconazole the amount of indole-3-acetic acid and gibberellic acid decreased significantly in the leaves. The changes recorded in the stems were at the level of error. Instead, the amount of endogenous abscisic acid increased 2.2-fold in leaves, and 1.8-fold in the stem (Fig. 6).

Thus, under the action of exogenous gibberellic acid the amount of endogenous indole-3-acetic, gibberellic and abscisic acids increased. Hormone accumulation was more active in eggplant leaves. Under the action of tebuconazole retardant, the amount of native indole-3-acetic and gibberellic acids in the stem and leaves decreased. In the leaves, the hormones were in trace amounts. Instead, abscisic acid content increased, dominating in the leaf.

Five cytokinin isoforms were identified in the leaf and eggplant stem under control conditions: zeatin (Z), zeatinriboside (ZR), zeatin-Oglucoside ( $\mathrm{ZG})$, isopentenyladenine (iP), isopentenyladenosine (iPA). Active zeatin and zeatinriboside, the content of which reached $429.3 \pm$ $17.99 \mathrm{ng} / \mathrm{g}$ of fresh weight, dominated in the stem. Instead, the content of inactive forms of zeatin-O-glucoside and isopentenyladenosine was equal to $240.8 \pm 11.19 \mathrm{ng} / \mathrm{g}$ of dry matter. Isopentenyladenine was found in trace amounts. Inactive eggplant leaves accumulated inactive isopentenyladenosine $(259.8 \pm 12.32 \mathrm{ng} / \mathrm{g}$ dry matter $)$ and active zeatinriboside and isopentenyladenine, the total content of which reached $128.4 \pm 6.07 \mathrm{ng} / \mathrm{g}$ of dry matter. Zeatin-O-glucoside and zeatin were found in trace amounts (Table 3 ).

During the treatment with a solution of gibberellic acid, there was a redistribution of cytokinin isoforms in the eggplant organs. Thus, inactive zeatin-O-glucoside (ZG), isopentenyladenine (iP) and isopentenyladenosine (iPA) accumulated in the stem. The content of the active forms decreased mainly due to zeatinriboside (ZR). Instead, there was a slight (at error level) increase in the content of inactive isopentenyladenosine (iPA). The content of isopentenyladenine (iP) decreased 4.5 -fold, whereas zeatin-O-glucoside (ZG), zeatin $(\mathrm{Z})$ and zeatinriboside $(\mathrm{ZR})$ were detected in trace amounts (Table 3 ).

After treatment with the tebuconazole solution, zeatin content in the stem decreased 1.3-fold, while the concentrations of isopentenyladenine (iP) and isopentenyladenosine (iPA) increased, respectively, 21.1 and
4.4 times. The leaves accumulated inactive isopentenyladenosine and iPA, the amount of which increased 1.6 times, while the content of isopentenyladenine (iP) and zeatiniboside (ZR) decreased, respectively, 5.6 and 2.0 times, respectively. In general, isopentenyladenosine (iPA) dominated in the organisms of eggplant (Table 3 ).

\section{Table 3}

Influence of gibberellic acid and tebuconazole on the content of cytokinin isoforms in stems and leaves of Solanum melongena $\mathrm{L}$. $\mathrm{cv}$. Diamond (ng/g of dry matter, treatment of plants in the budding phase was done on 10. 06. 2018, fixation of indicators in the phase of the beginning of fruit formation, $n=6, x \pm S E$ )

\begin{tabular}{|c|c|c|c|c|}
\hline & Indicator & Control sample & Gibberellic acid & Tebuconazole \\
\hline \multirow{6}{*}{$\frac{\Xi}{\infty}$} & Zeatin & $123 \pm 5.9$ & $109 \pm 4.4$ & $95 \pm 4.2^{*}$ \\
\hline & Zeatinriboside & $306 \pm 12.1$ & Traces & \\
\hline & Zeatin-O-glucoside & $209 \pm 9.9$ & $263 \pm 11.1^{*}$ & Traces \\
\hline & Isopentenyladenine & Traces & $133 \pm 5.2 * * *$ & $22 \pm 1.1^{* * *}$ \\
\hline & Isopentenyladenosine & $32.3 \pm 1.22$ & $170.7 \pm 7.23 * * *$ & $137.2 \pm 6.63 * * *$ \\
\hline & The amount of cytokinins & $670 \pm 29.2$ & $675 \pm 27.9$ & $254 \pm 11.9^{* * *}$ \\
\hline \multirow{6}{*}{ ङ્ } & Zeatin & & & \\
\hline & Zeatinriboside & $7.3 \pm 0.32$ & Traces & $14.8 \pm 0.63^{* * *}$ \\
\hline & Zeatin-O-glucoside & Traces & Traces & Traces \\
\hline & Isopentenyladenine & $121.1 \pm 5.75$ & $27,2 \pm 1.23^{* * *}$ & $21.5 \pm 1.01 * * *$ \\
\hline & Isopentenyladenosine & $259 \pm 12.3$ & $266 \pm 12.2$ & $423 \pm 19.9^{* * *}$ \\
\hline & The amount of cytokinins & $388 \pm 18.4$ & $293 \pm 13.4$ & $459 \pm 20.9^{*}$ \\
\hline
\end{tabular}

Note: $*-\mathrm{P}<0.05$; ** $-\mathrm{P}<0.01$; *** $-\mathrm{P}<0.001$, one-line comparisons by means of the difference between the mean values were calculated using the Bunferoni-corrected criterion ANOVA.

It is found that after foliar treatment with gibberellic acid and tebuconazole solutions, the number of fruits on eggplants increased by $26.1 \%$ and $43.5 \%$, respectively (Table 4 ). There was an increase in the fruit diameter and length. The average weight of one fetus under the action of gibberellic acid and tebuconazole increased by $17.4 \%$ and $26.9 \%$, respectively. Changing the quantitative indicators of productivity elements under the action of growth regulators has led to an improvement in biological crop productivity.

The most significant fruit yield from the plant increased after the application of tebuconazole ( $202 \pm 8.8 \mathrm{~g}$ per plant). When treated with gibberellic acid solution, this index increased by $116 \pm 5.7 \mathrm{~g}$ per plant (Table 4).

\section{Table 4}

Effect of gibberellic acid and tebuconazole on productivity elements in Solanum melongena L. cv. Diamond $(\mathrm{x} \pm \mathrm{SE}, \mathrm{n}=10)$

\begin{tabular}{lccc}
\hline \multicolumn{1}{c}{ Indicator } & $\begin{array}{c}\text { Control } \\
\text { sample }\end{array}$ & $\begin{array}{c}\text { Gibberellic } \\
\text { acid }\end{array}$ & Tebuconazole \\
\hline Fruit length, cm & $12.1 \pm 0.47$ & $13.9 \pm 0.56^{*}$ & $15.8 \pm 0.59^{* *}$ \\
Fruit diameter, cm & $3.7 \pm 0.13$ & $4.3 \pm 0.18^{*}$ & $4.9 \pm 0.22^{* *}$ \\
The average weight of one & $104 \pm 5.0$ & $122 \pm 5.5^{*}$ & $132 \pm 5.9^{* *}$ \\
fruit, g & $2.3 \pm 0.11$ & $2.9 \pm 0.14^{* *}$ & $3.3 \pm 0.16^{* * *}$ \\
$\begin{array}{l}\text { Number of fruits per plant, pcs. } \\
\text { Weight of fruits from one }\end{array}$ & $237 \pm 11.1$ & $353 \pm 16.8^{* * *}$ & $439 \pm 19.9^{* * *}$ \\
plant, g & & & \\
\hline
\end{tabular}

Note: treatment of plants in the budding phase was done on 10. 06. 2018, fixation of indicators in the phase of the beginning of fruit formation: * $-\mathrm{P}<0.05$; ** $\mathrm{P}<0.01$; *** $-\mathrm{P}<0.001$, one-line comparisons by means of the difference between the mean values were calculated using the Bonferroni-corrected ANOVA criterion.

\section{Discussion}

The study of the mechanisms of hormonal regulation of plant growth and development is one of the fundamental objectives of modern phytophysiology. With the participation of endogenous phytohormones, the management of physiological and biochemical processes in cells, tissues and organs is controlled, and the growth and development of the entire plant is regulated. The change in the rate of growth processes under the action of exogenous growth regulators, in particular gibberellin-like substances, is caused by changes in the balance of endogenous phytohormones (Rademacher, 2016; Khalloufi et al., 2017; Song et al., 2019). 
Therefore, the study of the effect of gibberellins and anti gibberellin preparations on the growth, development and productivity of cultivated plants deserves special attention (Jabir et al., 2017). Activation of growth processes and changes in the balance of endogenous hormones under the influence of exogenous gibberellins have been observed in organs of tomato plants (Khalloufi et al., 2017) and zucchini (Song et al., 2019).

It is established that the use of exogenous gibberellic acid and the antigibberellic triazole derivative of tebuconazole has been shown to lead to significant changes in the rate of growth of eggplants, as revealed in our previous studies (Kuryata et al., 2016; Rohach, 2017). The increase in linear size of shoots of plants treated with gibberellic acid and the weight of the raw material of the root of the stem and leaves, correlated with the increase in the content of endogenous growth promoters of gibberellic and indole-3-acetic acids in the stems and leaves. Instead, under the effects of tebuconazole, the content of gibberellic and indolyl-acetic acid in the stems and leaves of eggplant decreased, and abscisic acid increased against the background of inhibiting the growth of the stem and increasing the weight of fresh weight of all vegetative organs. The results obtained are similar to our previous ones and other authors' data on anatomo-morphological and phytohormonal changes recorded under the influence of triazole derivative paclobutrazole in winter rapeseed plants (Kuryata et al., 2005), potatoes, soybeans, alfalfa (Kuryatak et al., 2005; Tury et al., 2005), maize (Ahmad et al., 2017) and barley (Bakheta \& Hussein, 2014).

The content of indole-3-acetic acid in the eggplant stems after application of the retardant did not differ from the control sample, and the phytohormone was found in the leaves in trace amounts. According to other researchers, after the application of retardant of the 17-DMC group of quaternary ammonium salts, the content of gibberellins, indole-3-acetic acid and zeatin in the spring rapeseed decreased (Miljuvene et al., 2003). One of the major centers of auxin biosynthesis is located at the shoot apex (Bakheta \& Hussein, 2014; Khalloufi et al., 2017), which, in our opinion, led to the dominance of indole-3-acetic acid in the tissues of the eggplant stem in the control variant and thae variant with tebuconazole.

It is found that a relatively low content of gibberellins in the control and experimental variants was observed against a rather high level of abscisic acid in eggplant stems and leaves. Under the action of exogenous gibberellic acid and tebuconazole, the content of abscisic acid increased in the leaves and especially in eggplant stems. Similar results were obtained on soybean plants (Kang et al., 2014), tomatoes (Khalloufi et al., 2017) and flax (Kim et al., 2018).

Exogenous gibberellic acid has been found to enhance growth and formation processes (Rohach, 2017). Under the retardant action, the growth of the stalk to height was retarded, but branching increased and more leaves were formed (Kuryata et al., 2016). As a result of slowing the linear stem growth, plastic substances were directed to the formation of new leaves.

Chlorophyll synthesis in plants is known to be under control of the phytohormones of the cytokinin group (Vedenicheva \& Kosakivska, 2017). It is shown that the content of chlorophylls increased under the action of tebuconazole retardant, unlike gibberellic acid. The results obtained are consistent with the nature of cytokinin accumulation in leaves of experimental plants. Under the retardant action, the amount of cytokinins exceeded the control variant by $18.2 \%$, and after the use of gibberellic acid decreased by $24.5 \%$. Increase in the content of chlorophyll and cytokinin hormones under the influence of antigibberellic preparations is mentioned by other authors (Miljuvene et al., 2003; Liu et al., 2015).

Anatomic-morphological and physiological-biochemical changes under the action of growth regulators were realized through restructuring of donor-acceptor relationships and the redistribution of plastic matter flows between vegetative and generative organs (Rogach et al, 2016; Kuryata et al., 2019; Poprotska et al., 2019). Exogenous gibberellic acid and tebuconazole contributed to the formation of a more potent leaf apparatus, increasing the number of leaves, their mass and area. Increased photosynthetic activity enhanced the leaf donor function, and the increase in the number of generative organs intensified the acceptance of the newly formed plastic substances, which ultimately increased the culture productivity.

Thus, the use of exogenous multi-vector growth regulators - gibberellic acid and tebuconazole in soil-sand culture changed the speed of growth processes of eggplants, influenced the number of leaves per plant, their weight of crude substance, leaf area and mesostructure of leaves, balance of endogenous phytohormones in the aboveground vegetative organs, which led to the activation of the photosynthetic apparatus, resulting in increased biological productivity of the culture.

\section{Conclusions}

Plant regulators of growth and development with different directions of action - gibberellic acid (native hormone-stimulator) and triazole derivative retardant (tebuconazole), influencing the hormonal status of Solanum melongena L. cv. Diamond, caused changes in the morphogenesis, structure and function of leaf tissue.

Plant follicle height was found to be increased during foliar acid treatment, whereas tebuconazole inhibited stem elongation. Both regulators stimulated the formation of new leaves, the accumulation of their biomass, the increase in the area of the individual leaf blade and the area of leaves on the plant. Under the action of the preparations the biomass of stems and roots and the mass of dry matter of the whole plant also increased. Tebuconazole increased the content of the amount of chlorophylls $(a+b)$ in the leaves. Both regulators induced thickening of leaf blades due to the growth of chlorenchyma cells.

Exogenous gibberellic acid increased the accumulation of endogenous $\mathrm{GA}_{3}$, IAA and ABA in the stem and leaves, while tebuconazole decreased the $\mathrm{GA}_{3}$ and IOC content and increased the amount of ABA. After treatment with exogenous gibberellic acid, the pool of cytokinins in the leaves decreased. The stems were dominated by zeatin-O-glucoside (ZG) and isopentenyladenosine (iPA). Under the action of tebuconazole, the content of cytokinin isoforms in the leaves increased significantly. Due to the multi-directional action, growth regulators positively influenced the elements of eggplant productivity. The retardant tebuconazole was more effective. Thus, anatomic-morphological and structural-functional rearrangements in eggplant plants under to the effects of gibberellic acid and tebuconazole are due to changes in the balance and distribution of endogenous hormones. Increased photosynthetic activity, stimulation of growth processes of some organs of the plant and inhibition of others increased the biological productivity of the culture. The results obtained provide a new practical approach for increasing eggplant yield. At the same time, some issues regarding molecular and physiological mechanisms of the growth regulators under study require further investigation.

\section{References}

Ahammed, G. J., \& Yu, J. Q. (Eds.). (2016). Plant hormones under challenging environmental factors. Springer, Dordrecht.

Ahmad, I., Kamran, M., Meng, X., Ali, S., Bilegjargal, B., Cai, T., Liu, T., \& Han, Q. (2019). Effects of plant growth regulators on seed filling, endogenous hormone contents and maize production in semiarid regions. Journal of Plant Growth Regulation, 38(4), 1467-1480.

AOAC (2010). Official Methods of Analysis of Association of Analytical Chemist Intemational. 18th ed. Association of Analytical Chemist. Gaithersburg, Maryland.

Bakheta, M. A., \& Hussein, M. M. (2014). Uniconazole effect on endogenous hormones, proteins and proline contents of barley plants (Hordeum vulgare) under salinity stress $(\mathrm{NaCl})$. Nusantara Bioscience, 6(1), 39-44.

Cavalcante, Í. H. L., Nogueira e Silva, G. J., Cavacini, J. A., Araújo e Amariz, R., Tonetto de Freitas, S., Oliveira de Sousa, K. Â., Almeida da Silva, M., \& Gomes da Cunha, J. (2020). Metconazole on inhibition of gibberellin biosynthesis and flowering management in mango. Erwerbs-Obstbau, 62(1), 89-95.

Jabir, B. M. O., Kinuthia, K. B., Faroug, M. A., Awad, F. N., Everlyne, M. M., Ahmadzai, Z., \& Liu, L. (2017). Effects of gibberellin and gibberellin biosynthesis inhibitor (paclobutrazol) applications on radish (Raphanus sativus L.) taproot expansion and the presence of authentic hormones. International Journal of Agriculture and Biology, 19(4), 779-786.

Kang, S.-M., Radhakrishnan, R., Khan, A. L., Kim, M.-J., Park, J.-M., Kim, B.R., Shin, D.-H., \& Lee, I.-J. (2014). Gibberellin secreting rhizobacterium, Pseudomonas putida $\mathrm{H}-2-3$ modulates the hormonal and stress physiology of soybean to improve the plant growth under saline and drought conditions. Plant Physiology and Biochemistry, 84, 115-124.

Khalloufi, M., Martínez-Andújar, C., Lachaâl, M., Karray-Bouraoui, N., PérezAlfocea, F., \& Albacete, A. (2017). The interaction between foliar $\mathrm{GA}_{3}$ application and arbuscular mycorrhizal fungi inoculation improves growth in salinized tomato (Solanum lycopersicum L.) plants by modifying the hormonal balance. Journal of Plant Physiology, 214, 134-144. 
Khodanitska, O. O., Kuryata, V. G., Shevchuk, O. A., Tkachuk, O. O., \& Poprotska I. V. (2019). Effect of treptolem on morphogenesis and productivity of linseed plants. Ukrainian Journal of Ecology, 9(2), 119-126.

Kim, S.-K., Han, C.-M., Shin, J.-H., \& Kwon, T.-Y. (2018). Effects of paclobutrazol and prohexadione-ca on seed yield, and content of oils and gibberellin in flax grown in a greenhouse. Korean Journal of Crop Science, 63(3), 265-271.

Kosakivska, I. V., Vasyuk, V. A., Voytenko, L. V., Shcherbatiuk, M. M., Romanenko, K. O., \& Babenko, L. M. (2020). Endogenous phytohormones of fern Polystichum aculeatum (L.) Roth gametophytes at different stages of morphogenesis in vitro culture. Cytology and Genetics, 54(1), 23-30.

Kuryata, V. G., Negretskyi, V. A., Rogach, V. V., Golunova, L. A., Maznichenko, S. V., \& Guliaiev, B. I. (2005). Dija paklobutrazolu na aktyvnist' gibereliniv i vmist abscyzovoji kysloty v lystkah dejakyh sil's'kogospodars'kyh roslyn. [Effect of paclobutrazole on the activity of gibberellins and abscisic acid content in leaves of some agricultural plants]. Fiziologija i Biohimija Kul'turnyh Rastenij, 37(5), 452-457 (in Ukrainian).

Kuryata, V. G., \& Golunova, L. A. (2018). Peculiarities of the formation and functioning of soybean-rhizobial complexes and the productivity of soybean culture under the influence of retardant of paclobutrazol. Ukrainian Journal of Ecology, $8(3), 98-105$

Kuryata, V. G., \& Khodanitska, O. O. (2018). Features of anatomical structure, formation and functioning of leaf apparatus and productivity of linseed under chlormequatchloride treatment. Ukrainian Journal of Ecology, 8(1), 918-926.

Kuryata, V. G., \& Kravets, O. O. (2018). Features of morphogenesis, accumulation and redistribution of assimilate and nitrogen containing compounds in tomatoes under retardants treatment. Ukrainian Journal of Ecology, 8(1), $356-362$.

Kuryata, V. G., \& Polyvanyi, S. V. (2018b). Formation and functioning of sourcesink relation system of oil poppy plants under treptolem treatment towards crop productivity. Ukrainian Journal of Ecology, 8(1), 11-20.

Kuryata, V. G., Polyvanyi, S. V., Rogach, T. I., Khodanytska, O. O., \& Rogach, V. V. (2019a). Influence of chlormequat chloride on morphogenesis, formation of donor-acceptor system and production process of oil crops. In: Babych, M. M. (Ed.). The potential of modern science. Science Publishing, London. Vol. 1, pp. 130-156.

Kuryata, V. G., Polyvanyi, S. V., Shevchuk, O. A., \& Tkachuk, O. O. (2019b). Morphogenesis and the effectiveness of the production process of oil poppy under the complex action of retardant chlormequat chloride and growth stimulant treptolem. Ukrainian Journal of Ecology, 9(1), 127-134.

Kuryata, V. G., Rohach, V. V., Rohach, T. I., \& Khranovska, T. V. (2016). The use of antigibberelins with different mechanisms of action on morphogenesis and production process regulation in the plant Solanum melongena (Solanaceae). Visnyk of Dnipropetrovsk University, Biology, Ecology, 24(1), 230-234.

Kuryata, V. H., \& Polyvanyi, S. V. (2018a). Features of morphogenesis, donor-acceptor system formation and efficiency of crop production under chlormequat chloride treatment on poppy oil. Ukrainian Journal of Ecology, 8(4), $165-174$.

Liu, Y., Fang, Y., Huang, M., Jin, Y., Sun, J., Tao, X., Zhang, G., He, K., Zhao, Y., \& Zhao, H. (2015). Uniconazole-induced starch accumulation in the bioenergy crop duckweed (Landoltia punctata) I: Transcriptome analysis of the effects of uniconazole on chlorophyll and endogenous hormone biosynthesis. Biotechnology for Biofuels, 8, 57.
Mao, J.-P., Zhang, D., Zhang, X., Li, K., Liu, Z., Meng, Y., Lei, C., \& Han, M.-Y. (2018). Effect of exogenous indole-3-butanoic acid (IBA) application on the morphology, hormone status, and gene expression of developing lateral roots in Malus hupehensis. Scientia Horticulturae, 232, 112-120.

Miljuvene, L., Novickene, L., \& Gavelene, V. (2003). Jeffekt soedinenija 17-DMC na uroven' fitogormonov i rost rapsa Brassica napus [Effect of 17-DMC on phytohormone level and growth of rapeseed plants Brassica napus]. Fiziologija Rastenij, 50(5), 733-737 (in Russian).

Poprotska, I., Kuryata, V., Khodanitska, O., Polyvanyi, S., Golunova, L., \& Prysedsky, Y. (2019). Effect of gibberellin and retardants on the germination of seeds with different types of reserve substances under the conditions of skoto- and photomorphogenesis. Biologija, 65(4), 296-307.

Rademacher, W. (2016). Chemical regulators of gibberellin status and their application in plant production. Annual Plant Reviews, 49, 359-403.

Rogach, V. V., \& Rogach, T. I. (2015). Vplyv syntetychnyh stymuljatoriv rostu na morfofiziologichni harakterystyky ta biologichnu produktyvnist' kul'tury kartopli [Influence of synthetic growth stimulators on morphological and physiological characteristics and biological productivity of potato culture]. Visnyk of Dnipropetrovsk University, Biology, Ecology, 23(2), 221-224 (in Ukrainian).

Rogach, V. V., Poprotska, I. V., \& Kuryata, V. G. (2016). Dija giberelinu i retardantiv na morfogenez, fotosyntetychnyj aparat ta produktyvnist' kartopli [Effect of gibberellin and retardants on morphogenesis, photosynthetic apparatus and productivity of the potato]. Visnyk of Dnipropetrovsk University, Biology, Ecology, 24(2), 416-419 (in Ukrainian).

Rohach, V. V. (2017). Vplyv stymuljatoriv rostu na fotosyntetychnyj aparat, morfogenez i produkcijnyj proces baklazhana (Solanum melongena) [Influence of growth stimulants on photosynthetic apparatus, morphogenesis and production process of eggplant (Solanum melongena)]. Biosystems Diversity, 25(4), 297-304 (in Ukrainian).

Shevchuk, O. A., Tkachuk, O. O., Kuryata, V. G., Khodanitska, O. O., \& Polyvanyi, S. V. (2019). Features of leaf photosynthetic apparatus of sugar beet under retardants treatment. Ukrainian Journal of Ecology, 9(1), 115-120.

Song, S.-W., Lei, Y.-L., Huang, X.-M., Su, W., Chen, R.-Y., \& Hao, Y.-W. (2019). Crosstalk of cold and gibberellin effects on bolting and flowering in flowering Chinese cabbage. Journal of Integrative Agriculture, 18(5), 992-1000.

Tkachuk, O. O., Kuryata, V. G., \& Negretskyi, V. A. (2005). Vplyv retardantiv na vmist abscyzovoi' kysloty ta giberelopodibnyh rechovyn u lystkah kartopli [The effect of retardants on the content of abscisic acid and gibberellin-like substances in potato leaves]. Naukovi Zapysky Ternopilskoho Derzhavnoho Pedahohichnoho Universytetu, Seriia, Biolohiia, 24, 34-37 (in Ukrainian).

Upreti, K. K., Reddy, Y. T. N., Shivu Prasad, S. R., Bindu, G. V., Jayaram, H. L. \& Rajan, S. (2013). Hormonal changes in response to paclobutrazol induced early flowering in mango cv. Totapuri. Scientia Horticulturae, 150, $414-418$.

Van Emden, H. F. (2008). Statistics for terrified biologists. Blackwell, Oxford.

Vedenicheva, N. P., \& Kosakivska, I. V. (2017). Cytokininy jak reguljatory ontogenezu roslyn za riznyh umov zrostannja [Cytokinins as regulators of plant ontogenesis under different growth conditions]. Nash Format, Kyiv (in Ukrainian).

Zhou, Q., Gao, B., Li, W.-F., Mao, J., Yang, S.-J., Li, W., Ma, Z.-H., Zhao, X., \& Chen, B.-H. (2020). Effects of exogenous growth regulators and bud picking on grafting of grapevine hard branches. Scientia Horticulturae, 264, 109-186. 